\title{
Heterogeneity of the Haemagglutinin Responses to Salmonella minnesota R-Antigens in Rabbits
}

\author{
By KATHRYN K. NIXDORFF* \\ Department of Cell Biology, University of Kentucky, \\ Lexington, Kentucky, 40506, U.S.A. \\ AND S. SCHLECHT \\ Max-Planck-Institut für Immunbiologie, D-78 Freiburg-im-Breisgau, Germany
}

(Accepted for publication I2 February 1972)

\begin{abstract}
SUMMARY
Homologous and heterologous haemagglutinin responses in rabbits to heatkilled R-mutants of Salmonella minnesota (chemotypes ranging from $\mathrm{Ra}$ to $\mathrm{Re}$ ) were measured throughout the course of immunization. In each case the strongest response was directed against the homologous R-antigen, but in most cases crossreactions with antigens of heterologous $\mathrm{R}$-chemotypes were detected. Absorption studies with erythrocytes coated with R-lipopolysaccharides indicated that haemagglutinin reactions with homologous and heterologous $\mathrm{R}$-antigens in $\mathrm{R}$-antisera were due to several different populations of antibodies. In general, these populations consisted of: (i) antibodies strictly specific for the homologous antigen; (ii) antibodies reacting with the homologous antigen, but also able to react in varying degrees with heterologous $\mathrm{R}$-lipopolysacharides of more complete chemotypes; (iii) antibodies directed against internal portions of the R-oligosaccharide; and (iv) antibodies strictly specific for a less complete form of the R-oligosaccharide molecule. Characteristic responses were obtained for each of the R-mutants with respect to the presence or absence of any one of the above-mentioned antibody populations in antisera at a given period after immunization.
\end{abstract}

\section{INTRODUCTION}

Salmonella S-forms evoke in rabbits a variety of O-antibodies carrying specificities for different portions of the $\mathrm{O}$-specific polysaccharide. As a result, cross-reactions with a number of other salmonella species occur in such antisera because the cross-reacting O-antigens contain identical determinants (O-factors) consisting of di-, tri- or tetrasaccharides (Lüderitz et al. 1966; Lüderitz, 1970; Lüderitz, Westphal, Staub \& Nikaido, 1971). These crossreactions form the basis of the Kauffmann-White scheme of classification (Kauffmann, I966).

Similarly, antisera from rabbits immunized with salmonella R-mutants exhibit crossreactions with heterologous R-mutant lipopolysaccharides (Beckmann, Lüderitz \& Westphal, I964; Lindberg \& Holme, I968; Kenny \& Schlecht, I97I). Since these cross-reactions are not restricted to special R-chemotypes (Lüderitz et al. 1966; Lüderitz, 1970) they do not lead to a classification of R-mutants that reflects the chemical structure of the R-antigen. $\mathrm{R}$-mutants are therefore classified serologically by haemagglutination-inhibition reactions in highly diluted antisera (Beckmann et al. 1964) in which the heterologous antibody

* Present address: Max-Planck-Institut für Immunbiologie, D-78 Freiburg-im-Breisgau, Stübeweg 5I, Germany. 
populations have been diluted out. Only sporadic, weak reactions with R-antigens of heterologous chemotype occur in such inhibition systems.

Cross-reactions between salmonella $\mathrm{R}$-antisera and R-antigens of heterologous chemotype, which can be observed in passive haemagglutination tests, have not been well characterized; for example, it is not clear whether they represent reactions between an antigen and an antibody of imperfect 'fit' or whether the reactions are due to the presence of small amounts of antibodies specific for heterologous $\mathrm{R}$-antigens. It is known that immunization of rabbits with various salmonella $\mathrm{S}$-forms stimulates antibodies specific for $\mathrm{Ra}$-, $\mathrm{Rb}$ - and Rc-lipopolysaccharides (Schlecht, Böhlck \& Westphal, 197I). Information concerning the nature and extent of cross-reactions among $\mathrm{R}$-antigens in $\mathrm{R}$-antisera could indicate the purity of the antigen preparations used for immunization and could lead to a better understanding of the events occurring in vivo during the immunization process.

Haemagglutinin and precipitin responses in rabbits to heat-killed Salmonella minnesota $\mathrm{R}$-mutants ranging in chemotype from $\mathrm{Ra}$ to $\mathrm{Re}$ were measured in homologous systems throughout the course of immunization (Kenny \& Schlecht, I97I). High titres comparable to those found in O-antisera were usually obtained, showing that R-mutants, even those with the most deficient $\mathrm{R}$-oligosaccharide molecules, could be very potent immunogens. We now report a continuation of these studies. Homologous and heterologous responses against heat-killed $S$. minnesota R-mutants of well-defined chemotypes were measured by passive haemagglutination throughout the course of immunization. Specificities of the crossreactions were examined in high-titred antisera by absorption of serum samples with erythrocytes sensitized with the various alkali-treated R-lipopolysaccharides. Titres were again measured by passive haemagglutination.

\section{METHODS}

Bacterial strains. The R-mutants of Salmonella minnesota used are listed in Table I according to chemotype. These mutants were chosen for this investigation because they have been extensively investigated and the R-chemotypes have been clearly defined (Lüderitz et al. I966; Lüderitz, I970). Tests for R-character and chemotype during cultivation procedures have been previously described (Schmidt, Schlecht, Lüderitz \& Westphal, I969; Schlecht \& Westphal, I970; Kenny \& Schlecht, I97I).

Preparation of antigens for immunization. Bacteria were cultivated in Roux flasks on Beef Extract Agar (Kenny \& Schlecht, 197I), washed off the surface with sterile tap-water and heated for $2.5 \mathrm{~h}$ in a steam cabinet $\left(100^{\circ} \mathrm{C}\right)$. Heat-killed suspensions were washed three times with sterile tap-water and the concentration of bacteria was determined by direct microscopic count. The suspensions were adjusted to the proper concentration for immunization with $0.3 \%$ sterile $\mathrm{NaCl}$.

Antibody production. New Zealand white rabbits (Dr Seck, Hamburg, Germany, and S \& S Research, LaGrange, Kentucky, U.S.A.) weighing approximately 2 to $3 \mathrm{~kg}$ were given three injections of antigen $\left(2 \times 10^{10}\right.$ bacteria/ml $)$ intravenously (i.v.) at 5 -day intervals in graded volumes of $0 \cdot 25,0.5$ and $\mathrm{I} \cdot 0 \mathrm{ml}$, respectively. In each case two rabbits were immunized in parallel. Titres reported in the time curves of antibody formation (Fig. I) represent the geometric mean values of the separate titrations of sera from each rabbit. In the absorption experiments (Tables $3^{-6}$ ), titres on sera from each rabbit are reported individually.

Lipopolysaccharides. Lipopolysaccharides were extracted from R-mutants by the phenol/ chloroform/petroleum ether method described by Galanos, Lüderitz \& Westphal (I969) and used after activation with $\mathrm{NaOH}$ (Beckmann et al. 1964; Kenny \& Schlecht, I97I). 


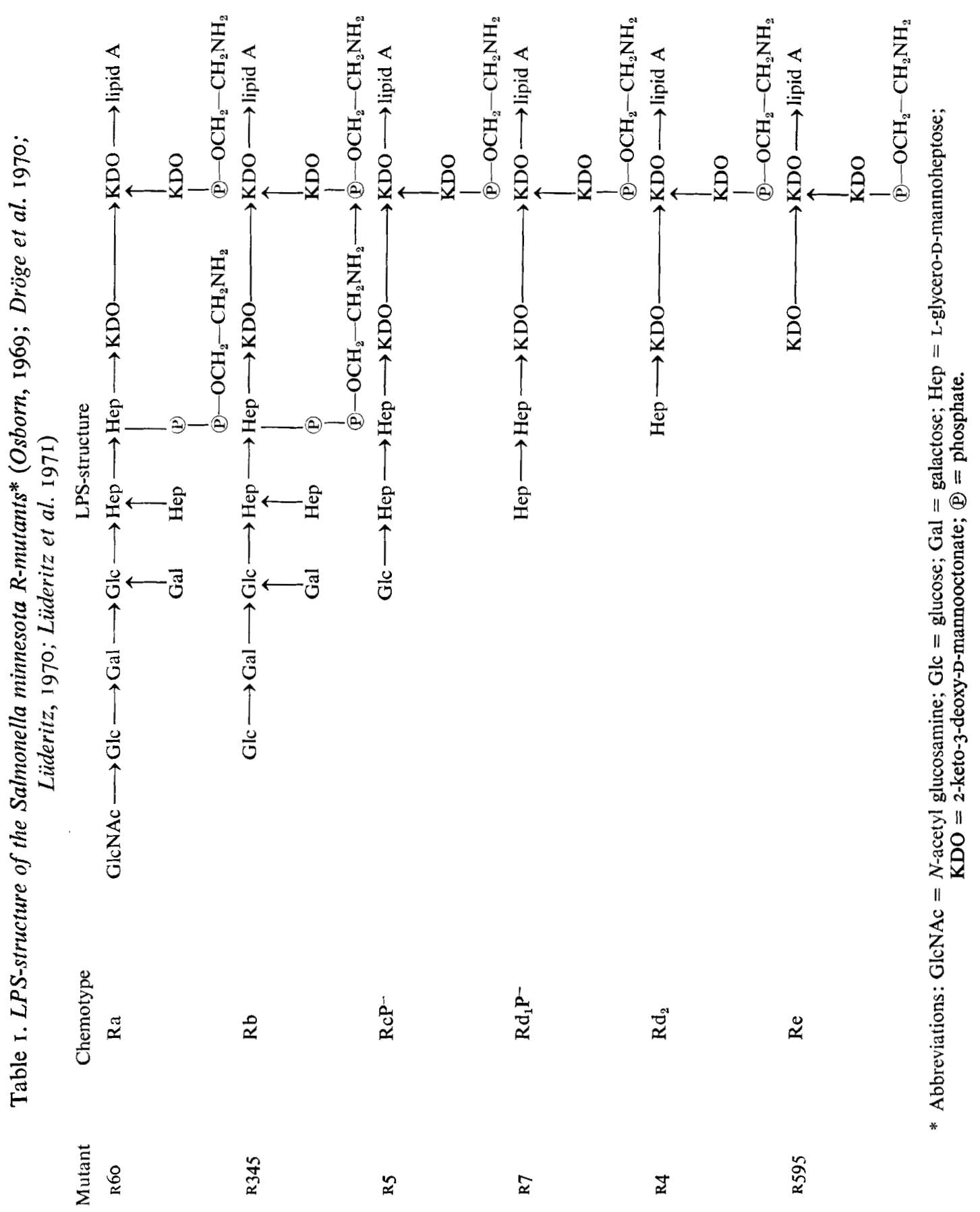


Haemagglutinin assay. Haemagglutinin titres were determined as previously described (Kenny \& Schlecht, I97I) using a Microtitrator apparatus (Metrimpex, Budapest, Hungary) according to Takatsy (I956).

Haemagglutination-inhibition. Alkali-treated lipopolysaccharides were used as inhibitors to ensure the same conditions as in the hemagglutination and the absorption tests. Suspensions containing $250 \mu \mathrm{g}$ lipopolysaccharide (LPS)/ml were diluted serially (twofold dilutions) by means of the microtitrator apparatus. To each dilution $(0.025 \mathrm{ml})$ an equal volume of antiserum containing three to four haemagglutinating units was added and the plates incubated $30 \mathrm{~min}$ at $37^{\circ} \mathrm{C}$. Finally, $0.025 \mathrm{ml}$ of sensitized sheep red blood cells (SRBC) was added, the plates re-incubated for $30 \mathrm{~min}$ at $37^{\circ} \mathrm{C}$ and then for $4 \mathrm{~h}$ at $23^{\circ} \mathrm{C}$. The results were recorded as the lowest concentration of LPS to give complete inhibition of haemagglutination.

Absorption tests. Sera to be absorbed were heat-inactivated for $30 \mathrm{~min}$ at $56{ }^{\circ} \mathrm{C}$. Two $\mathrm{ml}$ of a $\mathrm{I}: 5$ dilution of heat-inactivated serum were added to $2.0 \mathrm{ml}$ of LPS-sensitized SRBC sediment (Kenny \& Schlecht, I97I) and the mixture was incubated for I h at $37^{\circ} \mathrm{C}$. After incubation, the suspension was centrifuged and the serum was collected. In some cases, sera were absorbed a second time.

\section{RESULTS}

Homologous and heterologous haemagglutinin responses to Salmonella minnesota R-mutants. During immunization with $\mathrm{R}$-mutants ranging in chemotype from $\mathrm{Ra}$ to $\mathrm{Re}$, antisera were collected at intervals of 2 to 5 days. All sera were subjected to haemagglutinin analysis with SRBC coated with either homologous or heterologous R-lipolysaccharides (Fig. I).

In each case there was a distinct response in rabbits to the homologous immunizing R-antigen. Haemagglutinin titres to heterologous R-lipopolysaccharides, which were considerably lower than homologous titres, were also detectable in all antisera. In Ra-antisera cross-reaction only with Rb-LPS could be observed, while cross-reactions with all heterologous $\mathrm{R}$-antigens were detected in the other antisera.

Inhibition of haemagglutination with R-lipopolysaccharides. To test the purity of the lipopolysaccharide preparations, and hence that of the immunizing antigen, haemagglutinationinhibition tests were performed on R-antisera collected at the peak of the haemagglutinin responses. Antisera were diluted to give 3 to 4 haemagglutinating units in the test system. Alkali-treated lipopolysaccharides $(0.5$ to $250 \mu \mathrm{g} / \mathrm{ml})$ were used as inhibitors (Table 2). In this system the antisera are diluted beyond the level of any cross-reactions observed in the experiments of Fig. I, i.e. the antisera at these dilutions contain antibodies directed only against the homologous antigen. The homologous $\mathrm{R}$-lipopolysaccharides were extremely effective inhibitors in concentrations of $<0.5-8.0 \mu \mathrm{g} / \mathrm{ml}$, while the heterologous R-lipopolysaccharides were totally ineffective in concentrations as great as $250 \mu \mathrm{g} / \mathrm{ml}$. Thus there was not any detectable contamination of the various R-lipopolysaccharides with any R-LPS of another R-chemotype.

Nature of the observed cross-reactions. To investigate the nature of the cross-reactions observed, antisera against various $\mathrm{R}$-mutants $\left(\mathrm{Rb}, \mathrm{Rc}, \mathrm{Rd}_{2}\right.$ and $\left.\mathrm{Re}\right)$ were prepared and collected at the height of the haemagglutinin responses (day I5). Portions of each were absorbed with homologous or heterologous R-lipopolysaccharides attached to SRBC. The absorbed sera were subsequently tested for residual haemagglutinin activity with an R-LPS of each chemotype (Ra-Re). Two rabbits were immunized in parallel for each antigen and data for both animals are presented in Tables 3-6.

$R b$-antisera. Antisera to the $\mathrm{Rb}$ mutant showed a considerable degree of cross-reactivity 

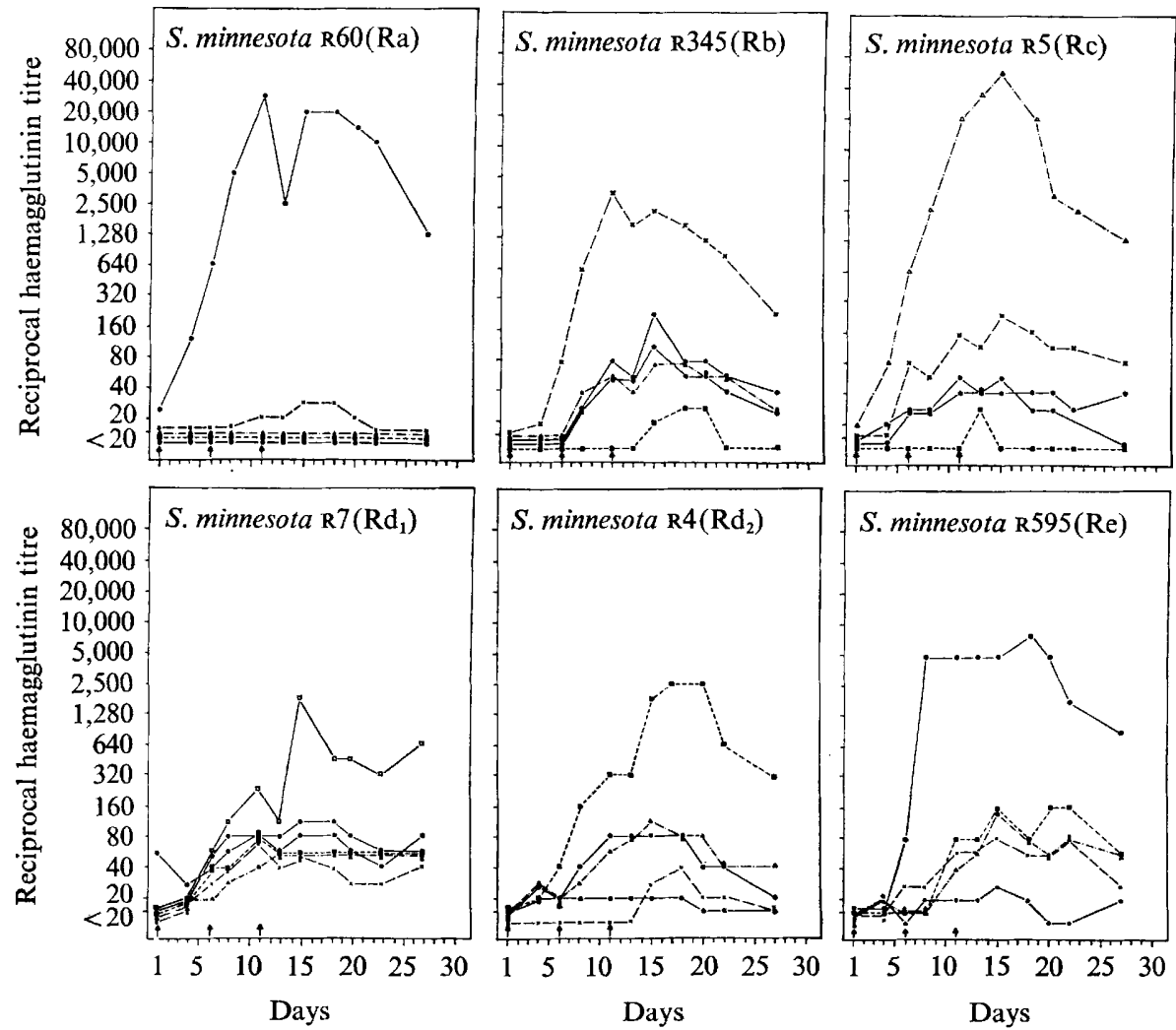

Fig. I. Haemagglutinin responses to homologous and heterologous R-antigens. Rabbits received three injections $(0.25,0.5$ and $\mathrm{I} \cdot 0 \mathrm{ml})$ of various heat-killed Salmonella minnesota $\mathrm{R}$-mutants in suspensions containing $2 \times 10^{10}$ bacteria/ml on days indicated by arrows. Each curve represents the geometric mean of titres of sera from two animals immunized in parallel. Immunizing antigens are listed at the top left of each graph. Curves represent the responses measured against SRBC sensitized with LPS from mutants of chemotypes Ra $(--)$, Rb $\left(\times--_{-}\right), \operatorname{Rc}(\triangle-\cdot \triangle)$, $\mathrm{Rd}_{1}(\square-\square), \operatorname{Rd}_{2}\left(\boldsymbol{\square}-\boldsymbol{D}^{-}\right)$and $\operatorname{Re}(\odot-\odot)$.

\section{Table 2. Haemagglutination-inhibition tests on Salmonella minnesota}

\section{R-antisera*}

Minimal amounts $(\mu \mathrm{g} / \mathrm{ml})$ of LPS inhibiting homologous haemagglutination (HA) systems $\ddagger$

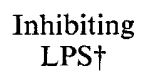

\begin{tabular}{|c|c|}
\hline $\mathrm{Ra}$ & $\mathrm{Rb}$ \\
\hline I & $>250$ \\
\hline$>250$ & I \\
\hline$>250$ & $>250$ \\
\hline$>250$ & $>250$ \\
\hline$>250$ & $>250$ \\
\hline$>250$ & $>250$ \\
\hline
\end{tabular}

$\begin{array}{cl}\mathrm{Rc} & \mathrm{Rd}_{1} \\ >250 & >250 \\ >250 & >250 \\ 8 & >250 \\ >250 & \geqslant 0.5 \\ >250 & >250 \\ >250 & >250\end{array}$

$\begin{array}{cc}\operatorname{Rd}_{2} & \mathrm{Re} \\ >250 & >250 \\ >250 & >250 \\ >250 & >250 \\ >250 & >250 \\ 2 & >250 \\ >250 & \mathrm{I}\end{array}$

* Antisera were collected from rabbits on day 15 after three injections $(0.25,0.5$ and $1.0 \mathrm{ml})$ at 5 -day intervals of a suspension containing $2 \times 10^{10}$ bacteria $/ \mathrm{ml}$.

$\dagger$ LPS was treated with alkali $(0.25 \mathrm{~N}-\mathrm{NaOH})$ at $56^{\circ} \mathrm{C}$ for $\mathrm{I} \mathrm{h}$.

* Antisera contained 3 to 4 haemagglutinating units. 


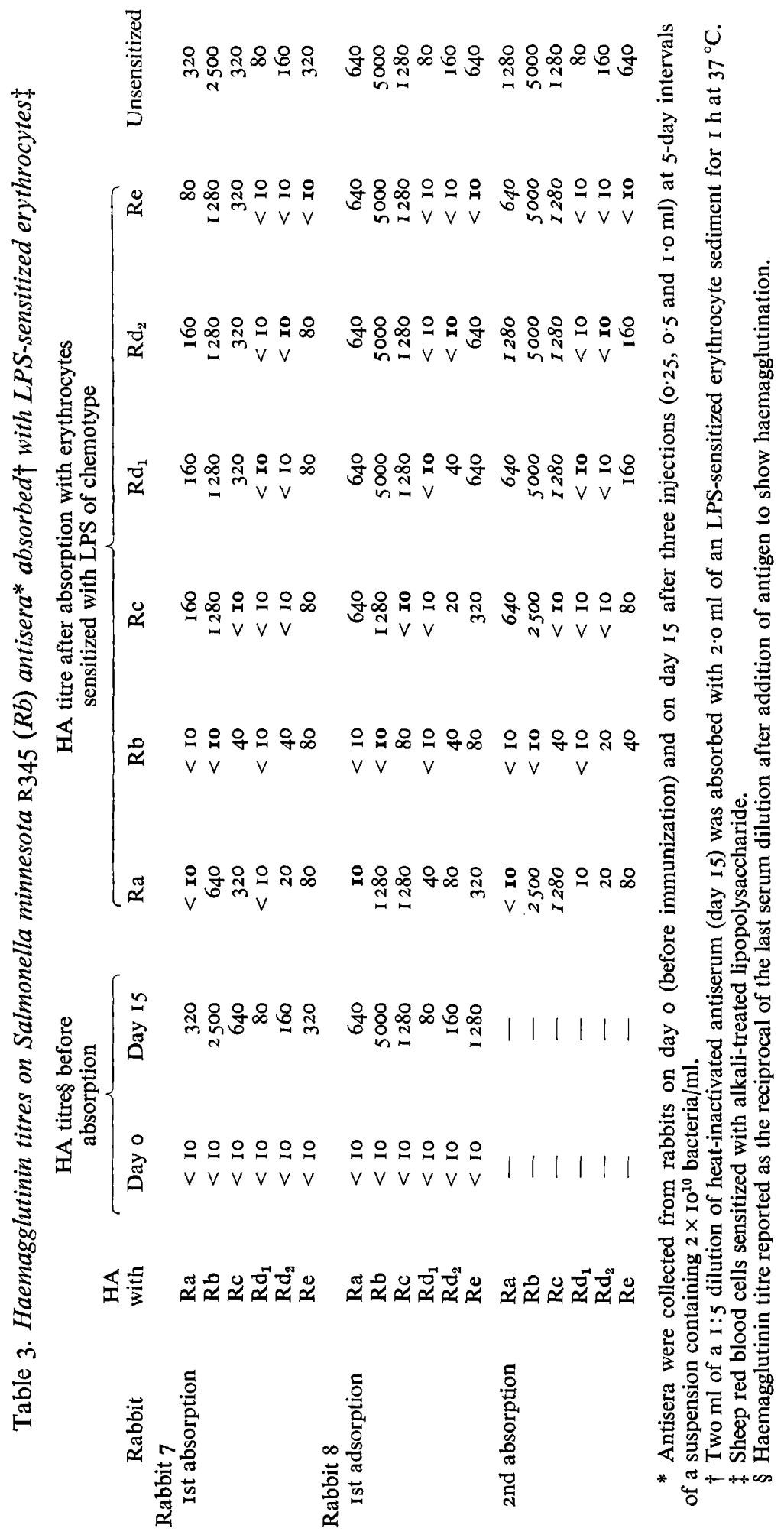


Heterogeneous response to salmonella $R$-antigens

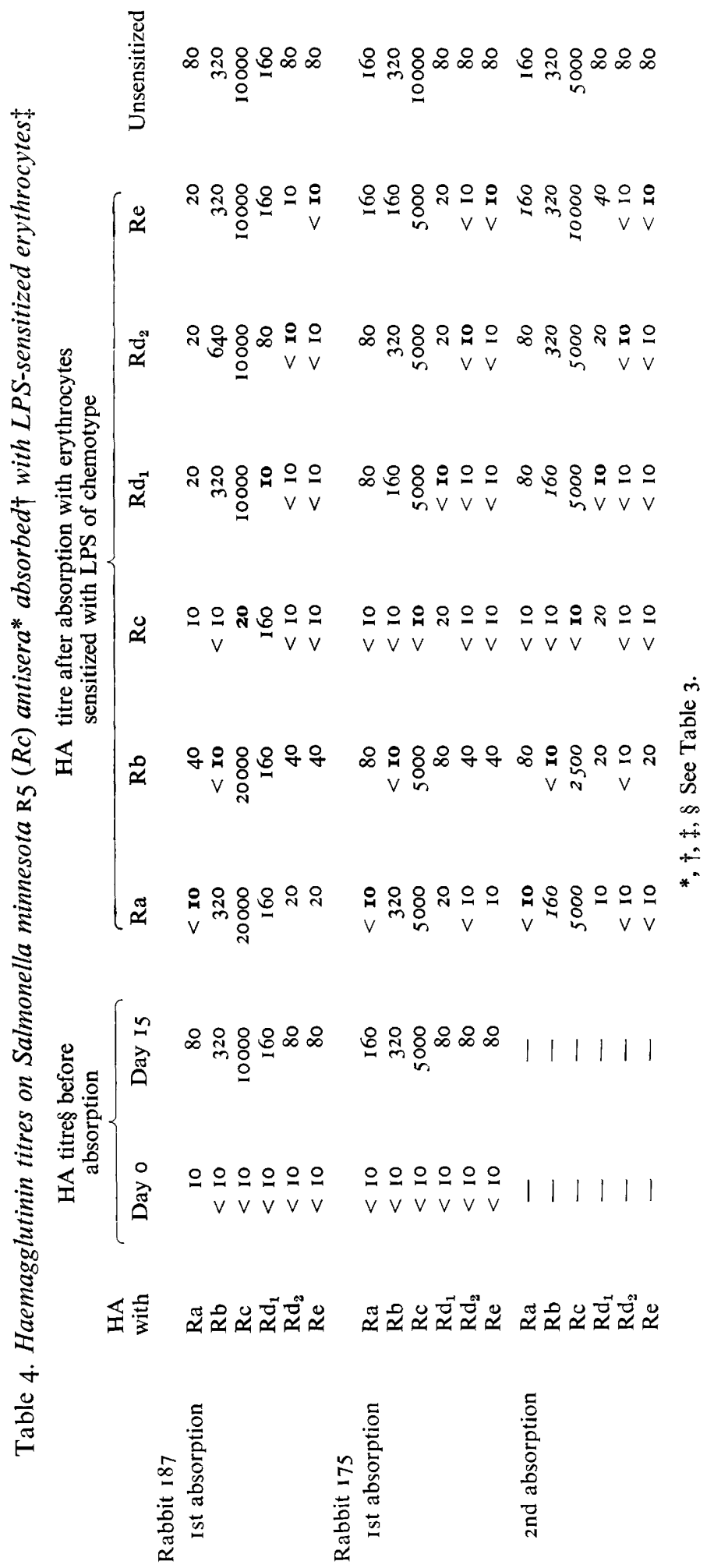




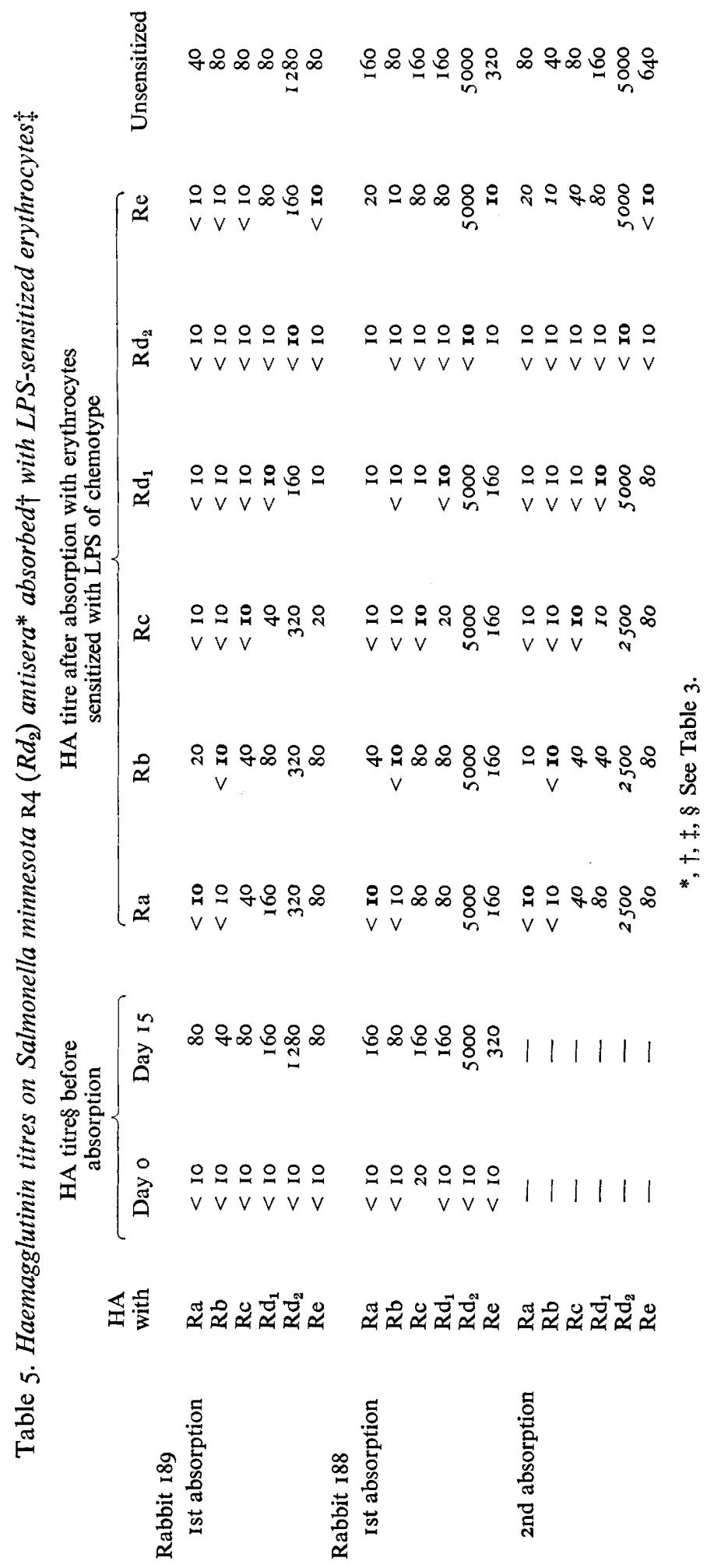


Heterogeneous response to salmonella $R$-antigens

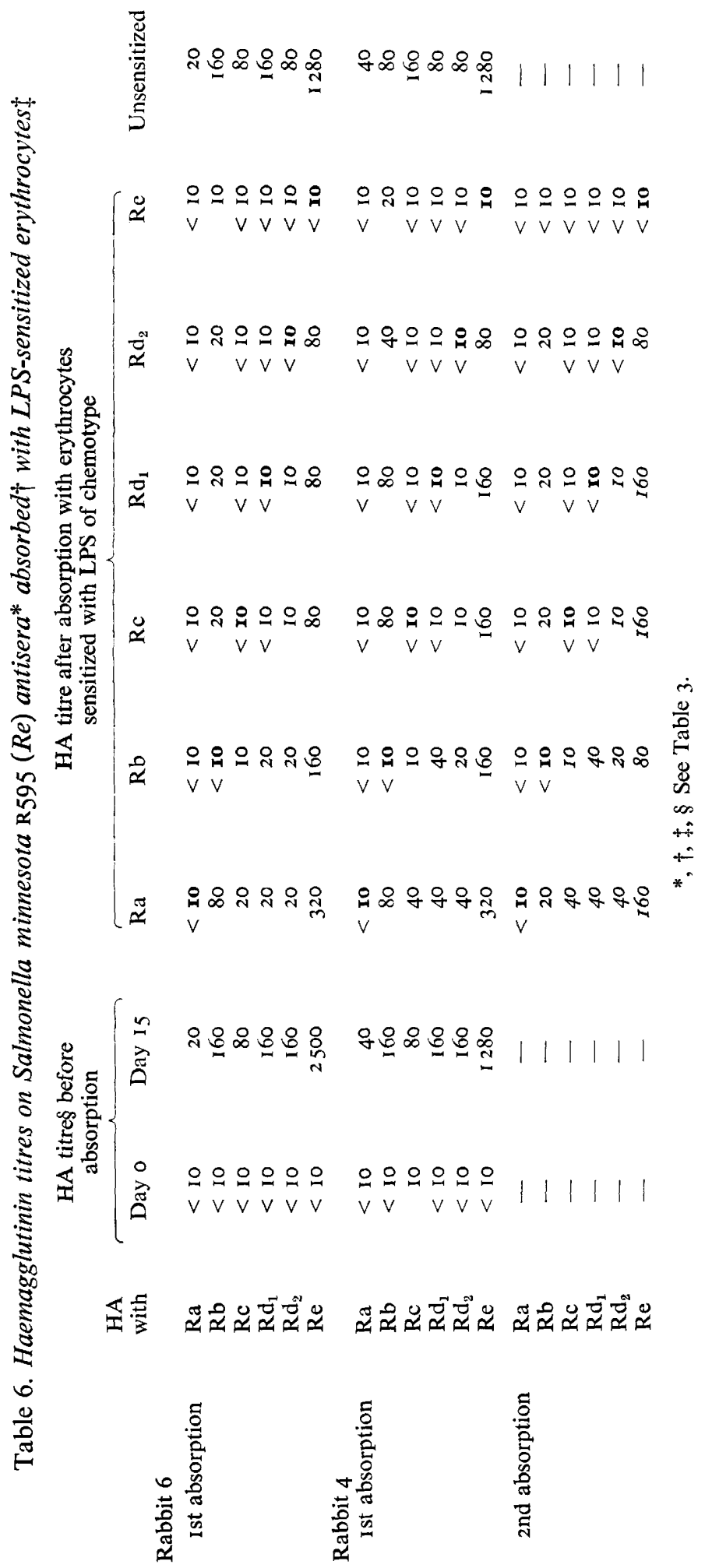


with all the R-lipopolysaccharides tested (haemagglutinin titres before absorption), even with the Re-LPS which is least related in structure to the Rb-LPS molecule. There was some variation in the actual values reported for rabbits 7 and 8 , but the general pattern was consistent for both antisera. Sera collected from both animals on day o (before immunization) showed no detectable reaction with any of the R-antigens.

Absorption of the antisera with the homologous Rb-LPS easily removed antibodies that reacted with the $\mathrm{Ra}$-, the $\mathrm{Rb}$ - and the $\mathrm{Rd}_{1}$-lipopolysaccharides, while antibodies reacting with the $\mathrm{Rc}$-, the $\mathrm{Rd}_{2}-$ and the $\mathrm{Re}$-lipopolysaccharides were only partially removed, even after two absorptions (data for rabbit 8). Those antibodies reacting with the Rc- and the Re-lipopolysaccharides were completely eliminated by absorption with their homologous (Rc- or Re-) antigens, but not by absorption with other antigens. However, antibodies reacting with the $\mathrm{Rd}_{2}$-LPS were completely absorbed by the $\mathrm{Rc}-$, the $\mathrm{Rd}_{1^{-}}$, the $\mathrm{Rd}_{2^{-}}$and the Re-antigens. All heterologous titres were promptly absorbed by the corresponding homologous R-LPS (Ra-titre by Ra-LPS, Rc-titre by Rc-LPS, etc.). On the other hand, certain haemagglutinin titres remained unchanged even after repeated absorption, e.g. the Rb- and the Rc-titres after absorption with Ra-LPS, the Ra- and the Rb-titres after absorption with the Rc-LPS and the Ra-, the $\mathrm{Rb}$ - and the Rc-titres after absorption with $\mathrm{Rd}_{1^{-}}, \mathrm{Rd}_{2^{-}}$or Re-LPS (see numbers in italics in Table 3). In addition none of the heterologous R-antigens could absorb any appreciable amounts of antibodies reacting with the homologous $\mathrm{Rb}$ lipopolysaccharide.

Unsensitized SRBC were unable to eliminate significant amounts of antibodies from the $\mathrm{Rb}$-antisera, even after two successive absorptions.

These results suggest the presence of several types of antibodies in the Rb-antisera. The greater proportion of antibodies as measured by haemagglutinin activity was strictly specific for the Rb-LPS, while a smaller proportion was specific for the Rc-LPS, or a related structure, and another proportion possibly specific for the Re-LPS. There were apparently antibodies also present that were able to react with the heterologous antigens in a less specific manner.

Rc antisera. Essentially similar results were obtained upon absorption of Salmonella minnesota $\mathrm{R} 5$ ( $\mathrm{Rc}$ ) antisera with the various R-lipopolysaccharides (Table 4). Absorption with the homologous Rc-LPS removed all antibodies except those reacting with the $\mathrm{Rd}_{1}$ antigen; these antibodies were completely eliminated only by absorption with the $\mathrm{Rd}_{1}-\mathrm{LPS}$ but were partially removed by absorption with the other R-antigens.

Again heterologous R-lipopolysaccharides were ineffective at absorbing antibodies homologous to the immunizing antigen, and even after two absorption procedures, several haemagglutinin titres remained unaffected (numbers in italics in Table 4). No absorbing capacity of unsensitized SRBC could be observed,

$R d_{2}$-antisera. Table 5 records the absorption of Salmonella minnesota $\mathrm{R} 4\left(\mathrm{Rd}_{2}\right)$ antisera. Absorption with the homologous $\mathrm{Rd}_{2}$-LPS removed all detectable antibodies cross-reacting with the heterologous $\mathrm{R}$ antigens but heterologous $\mathrm{R}$ antigens were totally ineffective in absorbing antibodies reacting with the $\mathrm{Rd}_{2}$-LPS in one antiserum (rabbit $\mathrm{I} 88$ ), and could only partially absorb these antibodies from the parallel antiserum (rabbit I 89).

For R-lipopolysaccharides of chemotypes $\mathrm{Ra}, \mathrm{Rb}, \mathrm{Rc}$ and $\mathrm{Rd}_{1}$, the general absorption pattern was that the closer the R-LPS was in structure to the $\mathrm{Rd}_{2}$-LPS, the more effective it was in absorbing out antibodies cross-reacting with different heterologous antigens. For example, the $\mathrm{Rd}_{1}$-LPS, which is closest in structure to the $\mathrm{Rd}_{2}$-LPS, could completely absorb antibodies reacting with $\mathrm{R}$-antigens of chemotypes $\mathrm{Ra}-\mathrm{Rd}_{1}$, while the $\mathrm{Rc}$-antigen eliminated antibodies reacting with the heterologous antigens of chemotypes $\mathrm{Ra}, \mathrm{Rb}$ and 
$\mathrm{Rc}$, but could not completely remove antibodies reacting with the $\mathrm{Rd}_{1}$-LPS. The Ra- and the $\mathrm{Rb}$-antigens were even less effective at absorbing antibodies reacting with the other heterologous R-lipopolysaccharides. Absorption with the Re-LPS eliminated completely only those antibodies reacting with the Re-antigen (rabbit I88).

These results indicated that the $\mathrm{Rd}_{2}$-antisera contained antibodies that were strictly specific for the $\mathrm{Rd}_{2}$-antigenic determinant and a further population of antibodies that was $\mathrm{Rd}_{2}$-specific but was also able to react in varying degrees with $\mathrm{R}$-lipopolysaccharides that are structurally more complete. The heterologous Re-LPS, however, did not react to any appreciable extent with either of the two groups of antibodies suggested above (see data for rabbit $\mathrm{I} 88$ ), i.e. absorption with the Re-antigen did not reduce the $\mathrm{Rd}_{2}$-titre and reduced titres to the other heterologous R-antigens only slightly. Antibodies with which the Reantigen did react probably represent a third population of antibodies directed against a portion of the $\mathrm{Rd}_{2}$-lipopolysaccharide and, in addition, against a portion of the Re-LPS. That these antibodies reacting with the Re-LPS are Re-LPS-specific is unlikely, as they were completely removed by absorption with the $\mathrm{Rd}_{2}$-LPS.

Re-antisera. Similar results were obtained with Salmonella minnesota R595 (Re) antisera absorbed with homologous and heterologous $\mathrm{R}$-antigens (Table 6). Absorption with the homologous Re-LPS removed all detectable antibodies reacting with the homologous and the heterologous R-antigens. Antibodies reacting with the Rb-LPS were incompletely removed, but after two absorptions with the Re-antigen they were completely eliminated (data for rabbit 4).

The absorption pattern with the heterologous $\mathrm{R}$-antigens was similar to that obtained with the $\mathrm{Rd}_{2}$-antisera (Table 5). None of the heterologous antigens could completely remove antibodies reacting with the homologous Re-LPS, even after two absorptions. Also, the closer the heterologous R-LPS structure was to that of the Re-mutant, the more effective it was in removing antibodies reacting with different heterologous R-antigens. Antibodies reacting with the Rb-LPS were apparently an exception, in that they were not totally eliminated by two absorptions with the $\mathrm{Ra}$-, the $\mathrm{Rc}-$, the $\mathrm{Rd}_{1}$ - or the $\mathbf{R d}_{2}$-antigens. These antibodies were removed most easily by the Rb-LPS, but it is unlikely that they were specific for the $\mathrm{Rb}$-antigen, as they could also be eliminated by absorption with the ReLPS, which was ineffective at absorbing Rb-specific antibodies in Rb-antisera (see Table 3).

The results indicated two principal populations of antibodies in the Re-antisera. One population was strictly specific for the Re-LPS and the other had Re-specificity, but could also react in varying degrees with the heterologous $\mathrm{R}$-antigens. Like the similar population of antibodies in the $\mathrm{Rd}_{2}$-antisera (Table 5), the reactivity of this latter population was apparently heterogenous with the various heterologous R-lipopolysaccharides, i.e. the RaLPS could react only with a certain portion of these antibodies whereas the $\mathrm{Rb}$-antigen could react with a larger portion, the Rc-LPS with an even greater portion, and so on.

In these antisera there were apparently no detectable antibodies strictly specific for the heterologous R-antigens.

\section{DISCUSSION}

The literature and also the present investigation shows that cross-reactions do occur in R-antisera with lipopolysaccharides from mutants of heterologous R-chemotypes (Lüderitz et al. 1966; Risse et al. 1967; Dröge, Ruschmann, Lüderitz \& Westphal, 1968; Lindberg \& Holme, 1968; Rowley, I968; Lüderitz, 1970).

One explanation might be that the lipopolysaccharides and immunizing antigens were not pure - because they contained R-lipopolysaccharides of other chemotypes which resulted 


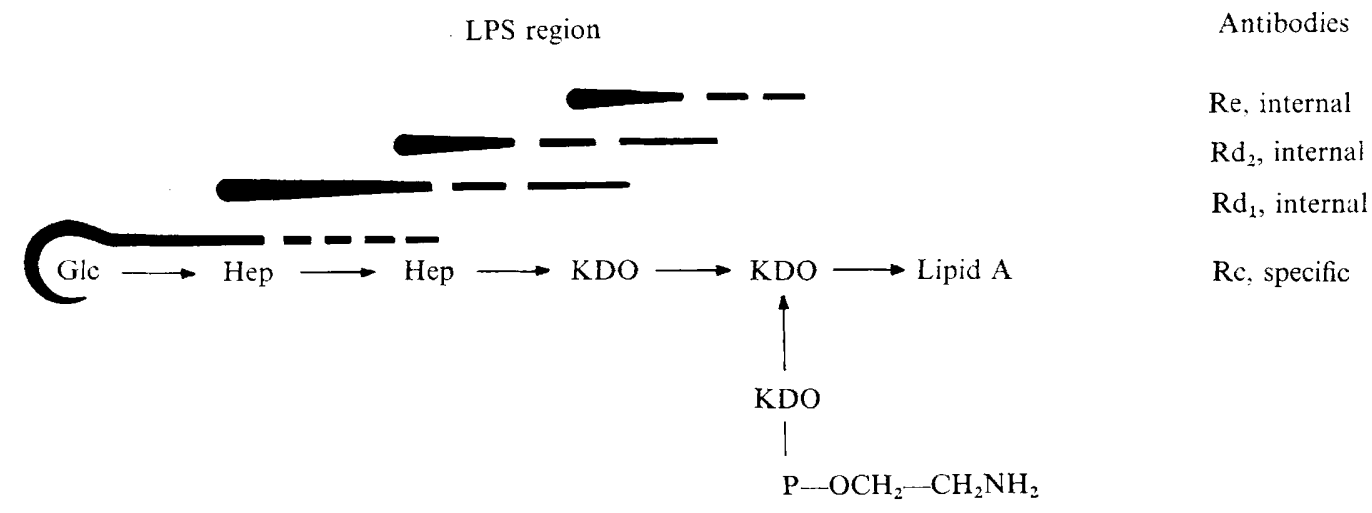

Fig. 2. Model for antibodies formed against the terminal structure and against internal portions of the Salmonella minnesota R5 (Rc) lipopolysaccharide molecule.

from leaky mutations (Risse et al. 1967) or mutations occurring during cultivation of the organisms or because incomplete R-LPS 'stubs' were formed during the biosynthesis of the $\mathrm{R}$-oligosaccharide. However, this possibility is unlikely judging from our haemagglutination inhibition tests (Table 2) and the inability of heterologous R-antigens to remove homologous antibodies after repeated absorptions (Tables 3 to 6). Furthermore, the mutants chosen for this study belong to well-defined chemotypes (Lüderitz et al. 1966; Risse et al. 1967; Dröge, Lehmann, Lüderitz \& Westphal, 1970; Lüderitz, 1970) and the method employed for extracting R-lipopolysaccharides (Galanos et al. 1969) assures particularly pure preparations.

The heterogenous serological reactions of $\mathrm{R}$-antisera must in some way reflect the immunological response to the antigens. They might have been due to antibodies formed against partial structures (R-factors) of the R-antigen molecule, considering that partial O-antigens consisting of 2 to 4 sugar units can act as determinants (O-factors) (Lüderitz, 1970; Lüderitz et al. I97I). With the Ra-mutant, the oligosaccharide portion of the R-LPS molecule is a decasaccharide. The other R-mutants have sequential deficiencies in oligosaccharide structure proceeding from chemotype $\mathrm{Rb}$ through $\mathrm{Re}$ (see Table $\mathrm{I}$ ). Thus, the more complete $\mathrm{R}$-core oligosaccharides contain potential antigenic determinants for the less complete. However, these determinants are internal in the complete molecule and therefore do not carry the strict specificity of the terminal immunodominent sugar of the less complete oligosaccharide molecule (Risse et al. 1967; Dröge et al. 1968; Lüderitz, 1970; Lüderitz et al. 1971). I these antigens do not undergo some form of degradation in vivo, the resulting antibodies would not only be directed against terminal, but also against internal oligosaccharide determinants.

Absorption experiments on the Rc-antisera (Table 4) suggest that the model of Fig. 2 is correct. All lipopolysaccharides ( $\mathrm{Ra}$ to $\mathrm{Re}$ ) absorbed completely or in part antibodies reacting with $\mathrm{Rd}_{1}-, \mathrm{Rd}_{2}$ - and the $\mathrm{Re}$-lipopolysaccharides (see data for rabbit 175 ). Absorptions with the $\mathrm{Rd}_{2}$ - and the Re-LPS, which completely eliminated antibodies reacting with both the $\mathrm{Re}$ - and the $\mathrm{Rd}_{2}$-antigens, indicate that only one antibody species is reacting with these antigens. The partial structure common to both antigens is of the type designated Re-internal (Fig. 2). Apparently the $\mathrm{Rd}_{1}$-LPS also reacts in the haemagglutination system with these antibody populations, for one absorption with $\mathrm{Rd}_{2}$ - or Re-LPS also reduced the $\mathrm{Rd}_{1}$-titre (see data for rabbit $\mathrm{I} 75$ ).

Analogous results concerning antibodies reacting with heterologous antigens were obtained with the $\mathrm{Rb}$-antisera (Table 3 ). $\mathrm{Rc}-, \mathrm{Rd}_{1}-$ and $\mathrm{Rd}_{2}$-LPS could completely eliminate 


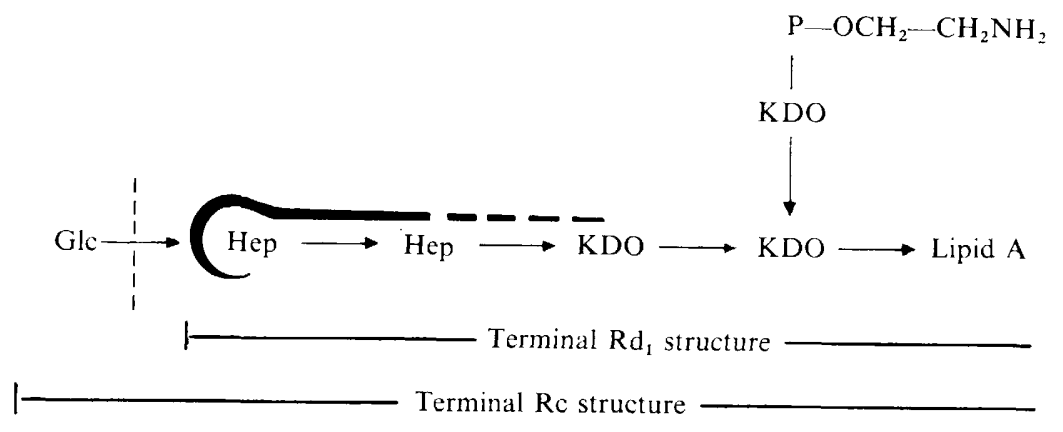

Fig. 3. Model for the proposed degradation of the Salmonella minnesota $\mathrm{R} 5$ (Rc) lipopolysaccharide molecule.

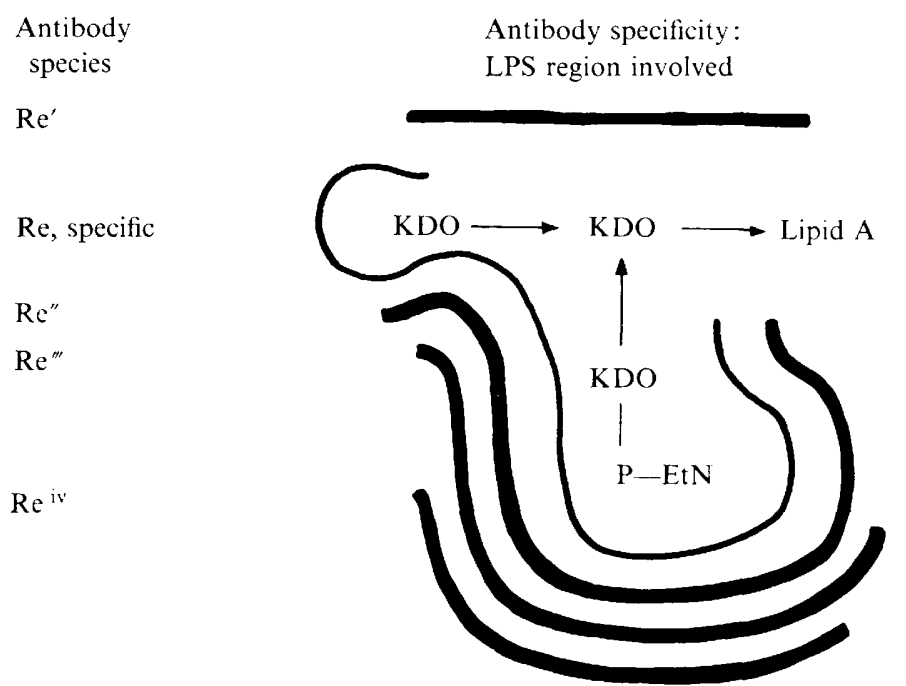

Fig. 4. Model depicting possible populations of antibodies formed against the Salmonella minnesota R595 (Re) lipopolysaccharide determinant. Only one type is strictly specific for the Re-LPS. The others can react in varying degrees with lipolysaccharides of chemotypes having more complete R-oligosaccharide molecules.

the $\mathrm{Rd}_{1}$ - and the $\mathrm{Rd}_{2}$-titres, and in addition reduce the Re-titre. However, the $\mathrm{Re}-\mathrm{LPS}$ completely absorbed the antibodies reacting with the $\mathrm{Rd}_{1^{-}}$, the $\mathrm{Rd}_{2^{-}}$and the $\mathrm{Re}$-lipopolysaccharides. These results indicate that these heterologous titres are due to antibodies designated Re-internal, or that the Re-titre may be determined in part by Re-specific antibodies. Evidence for antibodies formed against internal portions of the R-LPS molecule has also been obtained recently by E. Ruschmann at our institute.

Another possibility for the occurrence of heterologous R-antibodies might be that R-lipopolysaccharides undergo an enzymatic degradation in vivo (see model in Fig. 3). Chemical evidence for such degradation of lipopolysaccharide has not yet been shown, and it is very difficult to prove. However, absorption experiments on Rc-antisera (Table 4) possibly suggest that degradation has occurred. The heterologous $\mathrm{Rd}_{1}$-titre of antiserum $\mathrm{I} 87$ was reduced only by absorption with the $\mathrm{Rd}_{1}$-LPS and not by absorption with the Ra-, the $R \mathbf{R}$ - or the Rc-LPS, although all three lipopolysaccharides possess the internal $\mathbf{R d}_{1}$ structure. 
Table 7. Schematic representation of the various antibody populations found in the sera of rabbits immunized with Salmonella minnesota $R$-mutants

Reactivity with LPS

Anti-

serum

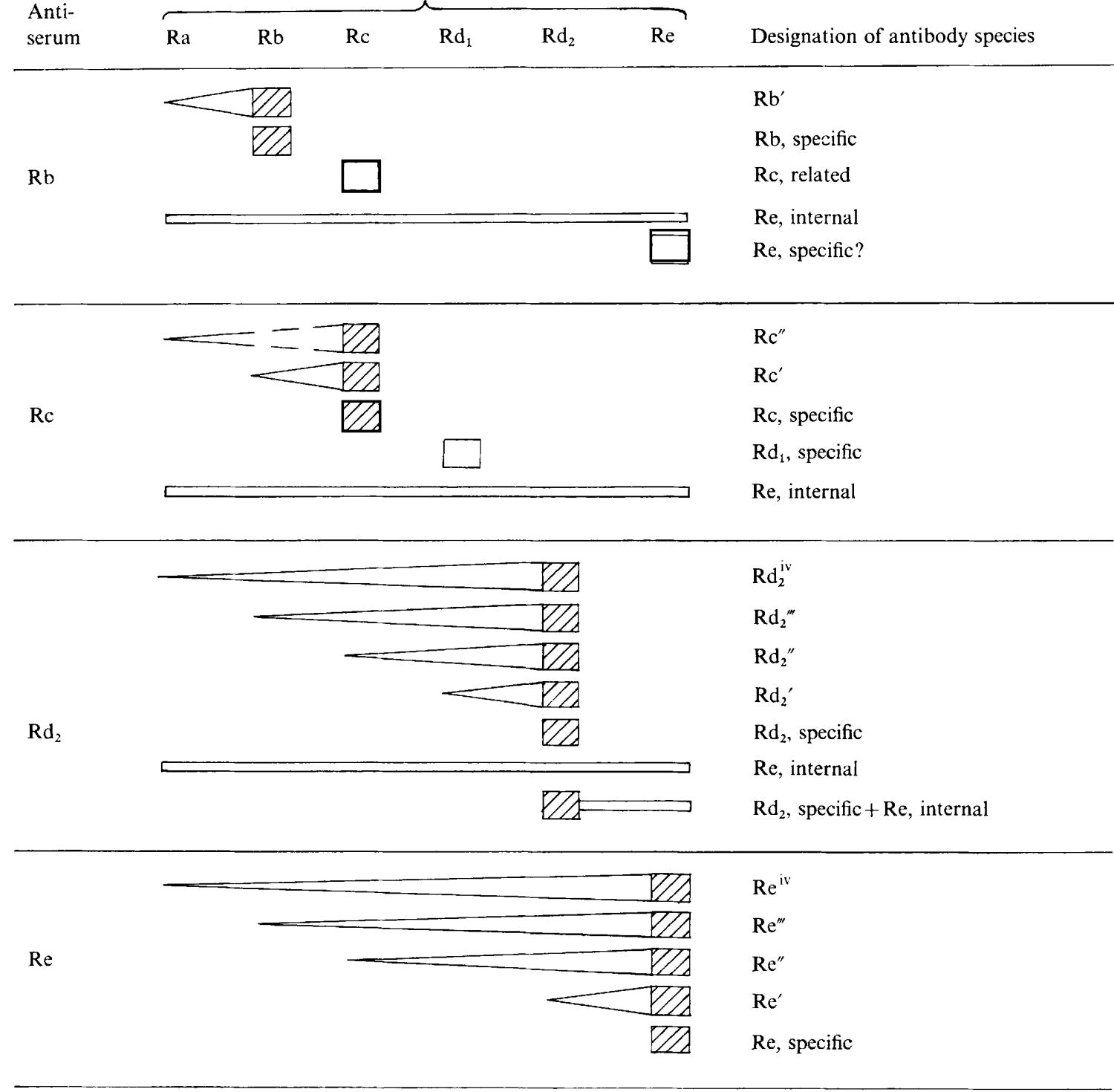

$\mathrm{Rb}$

$\operatorname{Rc} \operatorname{Rd}_{1} \quad \operatorname{Rd}_{2} \quad R$

Designation of antibody species

DA Specific antibody directed against the terminal structure of the lipopolysaccharide molecule.

Antibody population $\left(\mathrm{R} x^{\prime}\right)$ out of a family of antibodies directed against the $\mathrm{R} x$ determinant.

Specific antibody directed against the terminal structures of determinants possibly set free by degradation of the LPS molecule.

Antibody directed against a specific internal portion of the LPS molecule. 
Evidence for a possible degradation of the immunizing R-LPS antigen can also be found in absorption tests on Rb-antisera (Table 3), in which the heterologous Rc-titre was eliminated easily and completely only by absorption with the Rc-LPS. Similarly, antibodies reactive with Re-LPS in Rb-antisera were easily eliminated by absorption with Re-LPS, while absorption of these antibodies by all other R-antigens was weak and retarded (Table 3 ).

From studies on $\mathrm{O}$-antigens it is known that a family of antibodies may be produced against the same immunodominant sugar, covering different lengths of the determinant region (Lüderitz, 1970, Lüderitz et al. 197I). Our absorption tests suggest that such antibody populations also exist in $\mathrm{R}$-antisera; these antibodies reacted with $\mathrm{R}$-lipopolysaccharides of more complete chemotypes. A model for Re-antisera is presented in Fig. 4. Absorption with Re-LPS (Table 6) removed all homologous antibodies, including a heterogenous population capable of reacting with heterologous $\mathrm{R}$-lipopolysaccharides to varying degrees. Thus, Ra-LPS could absorb out only a small proportion of these antibodies. $\mathrm{Rb}$-LPS removed a greater proportion, while the $\mathrm{Rc}$ - and the $\mathrm{Rd}_{1}$-antigens eliminated an even greater proportion. The $\mathrm{Rd}_{2}$-LPS could absorb out the entire population of antibodies reacting with the heterologous antigens. Similar populations of antibodies were also detected in $\mathrm{Rd}_{2}$-antisera (Table 5), Rc-antisera (Table 4) and Rb-antisera (Table 3 ). As it is known that antibodies formed against a single determinant can be heterogeneous with respect to affinity (Pressmann, Roholt \& Grossberg, 1970; Eichmann \& Greenblatt, I97I), our results might be explained on this basis.

A summary of the several proposed types or populations of antibodies found in each of the antisera tested is presented schematically in Table 7 .

Antibody responses to salmonella $\mathrm{R}$-antigens are apparently similar to the responses to $\mathrm{O}$-antigens in that internal structures of the $\mathrm{R}$-oligosaccharide chain act as immunodominant groups. While the determinant groups of $\mathrm{O}$-antigens occur several times on each polysaccharide chain (repeating units), they appear only once in the R-oligosaccharide (Osborn, I969; Lüderitz, 1970). This may be the reason that $\mathrm{R}$-antisera, in contrast to $\mathrm{O}$-antisera, contain relatively low titres of antibodies directed against internal groups; the main portion of antibodies to $\mathrm{R}$-antigens is formed against terminal structures. Antisera highly specific for the terminal structures of the different salmonella R-antisera are obtained by absorption with R-lipopolysaccharides of the next higher and/or the next lower chemotype. Heterologous titres that still remain can be absorbed out individually. By this method only specific Re-titres will be markedly reduced, for their specificity is probably due mainly to the KDO branch sugar, which is accessible in all salmonella R-lipopolysaccharides.

Recently Galanos, Lüderitz \& Westphal (197I) have detected antibodies to lipid A in several salmonella R-mutant antisera. The possibility that a small portion of the heterologous titres observed in our studies were due to antibodies directed against lipid A cannot be ruled out. However, they do not apparently play a great role in the context of this investigation.

During a portion of this investigation K.K.N. was the recipient of an Alexander von Humboldt Foundation post doctoral fellowship. This investigation was supported in part by a USPHS biomedical research grant (5-S05-07 I 14-03) and by a research grant from the Burroughs Wellcome Fund. The technical assistance of Helga Breer and Elvira Fischer is gratefully acknowledged. 


\section{REFERENCES}

BeckmanN, I., LÜderitz, O. \& WestPhal, O. (1964). Zur Immunchemie der somatischen Antigene von Enterobacteriaceae. IX. Serologische Typisierung von Salmonella R-Antigen. Biochemische Zeitschrift 339, 40I-4I5.

Dröge, W., Lehmann, V., Lüderitz, O. \& Westrhal, O. (I970). Structural investigations on the 2-keto-3deoxyoctonate region of lipopolysaccharides. European Journal of Biochemistry 14, 175-184.

Dröge, W., Ruschmann, E., Lüderitz, O. \& Westphal, O. (1968). Biochemical studies on lipopolysaccharides of Salmonella R-mutants. 4. Phosphate groups linked to heptose units and their absence in some R-lipopolysaccharides. European Journal of Biochemistry 4, 134-1 38.

EichmaNN, K. \& GREENBLATT, J. (I97I). Relationships between relative binding affinity and electrophoretic behaviour of rabbit antibodies to streptococcal carbohydrates. Journal of Experimental Medicine $\mathbf{1 3 3}$, 424-44I.

Galanos, C., LÜDeritz, O. \& Westrhal, O. (I969). A new method for the extraction of R-lipopolysaccharides. European Journal of Biochemistry 9, $245-249$.

Galanos, C., Lüderitz, O. \& WestPhal, O. (I97I). Preparation and properties of antisera against the lipid A component of bacterial lipopolysaccharides. European Journal of Biochemistry 24, I I6-I22.

Kauffmann, F. (1966). The Bacteriology of Enterobacteriacede, pp. 55-304. Copenhagen: Munksgaard.

KenNy, K. \& Schlecht, S. (I97I). Antibody response in rabbits to Salmonella minnesota R-mutants. Zentralblatt für Bakteriologie, Parasitenkunde, Infektionskrankheiten und Hygiene (Abteilung I, Originale) 217, 183-197.

LindBerg, A. A. \& Holme, T. (I968). Immunochemical studies on cell-wall polysaccharide of rough mutants of Salmonella typhimurium. Journal of General Microbiology 52, 55-66.

LÜDERITZ, O. (1970). Recent results on the biochemistry of the cell wall lipopolysaccharides of Salmonella bacteria. Angewandte Chemie 9, 649-663.

Lüderitz, O., Galanos, C., Risse, H. J., Ruschmann, E., Schlecht, S., Schmidt, G., Schulte-HolthaUSEn, H., WheAt, R., WeStPhal, O. \& SchlosshaRdt, J. (I966). Structural relationships of Salmonella $\mathrm{O}$ and $\mathrm{R}$ antigens. Annals of the New York Academy of Sciences 133, 349-374.

Lüderitz, O., WeSTPHAL, O., StAub, A. M. \& NikaIDo, H. (I97I). Isolation and chemical characterization of bacterial lipopolysaccharides. In Microbial Toxins, vol. Iv. Bacterial Endotoxins, pp. 145-233. Edited by G. Weinbaum, S. Kadis \& S. J. Ajl. New York: Academic Press.

Osborn, M. J. (1969). Structure and biosynthesis of the bacterial cell wall. Annual Review of Biochemistry $3^{8}, 501-538$.

Pressmann, D., Roholt, O. A. \& Grossberg, A. L. (1970). Chemical and structural differences between antibodies capable of binding a particular hapten group: evidence for limited heterogeneity. Annals of the New York Academy of Sciences 169, 65-71.

Risse, H. J., Dröge, W., Ruschmann, E., LÜderitz, O., Westrhal, O. \& Schlosshardt, J. (1967). Eine neue Gruppe von Salmonella R-Mutanten. Serologische und biochemische Analyse des Heptosekerns von Lipopolysacchariden aus Salmonella minnesota and Salmonella ruiru Mutanten. European Journal of Biochemistry r, 216-232.

Rowley, D. (1968). Sensitivity of rough Gram-negative bacteria to the bactericidal action of serum. Journal of Bacteriology 95, I647-I650.

Schlecht, S., BöHLCK, I. \& WeSTPHAL, O. (197I). Nachweis von Antikörpern gegen Salmonella R-Antigene in Salmonella O-Antiseren. Zentralblatt für Bakteriologie, Parasitenkunde, Infektionskrankheiten und Hygiene (Abteilung I, Originale) 216, 472-482.

Schlecht, S. \& WestPHAL, O. (1970). Untersuchungen zur Typisierung von Salmonella R-Formen. 4. Mitteilung: Typisierung von $S$. minnesota-Mutanten mittels Antibiotica. Zentralblatt für Bakteriologie, Parasitenkunde, Infektionskrankheiten und Hygiene (Abteilung I, Originale) 213, 356-38I.

SchmidT, G., Schlecht, S., LÜDERTtz, O. \& WeStPhal, O. (1969). Untersuchungen zur Typisierung von Salmonella R-Formen. I. Mitteilung: Mikrobiologische und serologische Untersuchungen an Salmonella minnesota Mutanten. Zentralblatt für Bakteriologie, Parasitenkunde, Infektionskrankheiten und Hygiene (Abteilung I, Originale) 209, 483-496.

Takatsy, S. (1956). The use of spiral loops in serological and virological micro-methods. Acta microbiologica hungarica 3, 19I-202. 